Original Article

\title{
Recovery Process of Standing Postural Control in Hemiplegia after Stroke
}

\author{
Ryuzo Yanohara, RPT ${ }^{1)^{*}}$, Toshio Teranishi, RPT, PhD ${ }^{2)}$, Yutaka Tomita, RE, PhD ${ }^{3)}$, \\ Genichi Tanino, RPT ${ }^{1,3)}$, Yoshiya Ueno, RPT ${ }^{1)}$, Shigeru Sonoda, MD, $\mathrm{PhD}^{1,3)}$ \\ 1) Fujita Health University Nanakuri Sanatorium: 424-1 Ohdori, Tsu, Mie 514-1295, Japan \\ 2) Fujita Health University School of Health Sciences, Japan \\ 3) Fujita Memorial Nanakuri Institute, Fujita Health University, Japan
}

\begin{abstract}
Purpose] The aim of this study was to investigate the recovery process of standing postural control in hemiplegia after stroke. [Subjects and Methods] Thirty-four inpatients with hemiparesis after first-onset stroke were included in this study. We measured the center of pressure fluctuations during quiet standing using a force platform at 2, 4, and 6 weeks after admission. We assessed weight-bearing asymmetry, and velocity and amplitude of body sway. [Results] Weight-bearing asymmetry diminished in the first 2 weeks of observation. Velocity of body sway also decreased significantly in the first 2 weeks, though its amplitude only decreased significantly after 4 weeks of observation. [Conclusion] Amplitude of body sway requires a longer time for significant improvement than weightbearing asymmetry and velocity of body sway. Although the loading function of the paretic lower limb improved at an early stage, attainment of optimum postural control, including management of the affected paretic lower limb, requires much time.

Key words: Postural balance, Hemiplegia, Recovery of function
\end{abstract}

(This article was submitted Apr. 2, 2014, and was accepted May 16, 2014)

\section{INTRODUCTION}

Postural control involves controlling the body's position in space for the dual purpose of stability and orientation. Postural orientation is defined as the ability to maintain an appropriate relationship between the body segments and between the body and the environment for a task. Postural stability, or balance, is the ability to maintain the body in equilibrium ${ }^{1)}$. Postural control is often impaired after stroke. We focused on postural control during quiet standing in this study. Quiet standing postures of hemiplegics after stroke are characterized by weight-bearing asymmetry with a shift in the mean position of the center of pressure (COP) toward the unaffected side ${ }^{2)}$, and an increase of body sway compared to age-matched healthy controls ${ }^{3,4)}$. Body sway has a negative correlation with gait velocity ${ }^{5)}$ and is related to the risk of falling ${ }^{6,7)}$.

Stable quiet standing supposedly contributes to improved gait ability and the prevention of falls. Although many researchers have reported on the characteristics of standing postural control in hemiplegics after stroke, few articles have mentioned the recovery process. Therefore, we measured the COP fluctuations of hemiplegic stroke

*Corresponding author. Ryuzo Yanohara (E-mail: yanohara@ fujita-hu.ac.jp)

(C2014 The Society of Physical Therapy Science. Published by IPEC Inc. This is an open-access article distributed under the terms of the Creative Commons Attribution Non-Commercial No Derivatives (by-ncnd) License $<$ http://creativecommons.org/licenses/by-nc-nd/3.0/> . patients during quiet standing using a force platform at 2 , 4 , and 6 weeks after hospital admission. The subjects were patients who were admitted to the sub-acute rehabilitation ward at the Fujita Health University Nanakuri Sanatorium, where we perform intensive rehabilitation for improvement of paretic function and activities of daily living (ADL). The purpose of this study was to investigate the recovery process of quiet standing postural control during rehabilitation treatment.

\section{SUBJECTS AND METHODS}

Thirty-four inpatients with hemiplegia after first-onset stroke were included in this study. The subjects had the ability to maintain independent unsupported quiet standing for 60 seconds, but could not walk independently at 2 weeks after admission even with orthoses or parallel bars. Subjects who had cognitive or psychiatric problems that impaired their ability to follow instructions and those who had neuromuscular impairment before the onset of the stroke were excluded from the study. Subjects' characteristics at 2 weeks after admission are shown in Table 1. Brunnstrom recovery stage $^{8)}(\mathrm{BRS})$ of the lower extremities, the lower extremity position sense item of the Stroke Impairment Assessment Set $^{9,10)}$ (SIAS), and motor subscore, cognitive subscore, and gait item score of the Functional Independence Measure ${ }^{11)}$ (FIM) were assessed at 2, 4, and 6 weeks after admission and are shown in Table 2.

COP was measured using a force plate system (Twingravicoder G6100; ANIMA Corp.). Subjects stood with their arms at their trunk sides and with one foot on each of 
Table 1. Characteristics of subjects $(\mathrm{N}=34)$

\begin{tabular}{lc}
\hline Age (mean $\pm \mathrm{SD})$ & $59.8 \pm 13.7$ years \\
Time post-stroke (mean $\pm \mathrm{SD})$ & $45.7 \pm 13.6$ days \\
Gender (number) & men (28) women (6) \\
Type of stroke (number) & infarction (16) hematoma (18) \\
Affected side (number) & left (17) right (17) \\
\hline
\end{tabular}

the two force plates. The feet were positioned parallel and they were $10 \mathrm{~cm}$ apart medially. Subjects wore their own shoes, but did not put on orthoses. Subjects stood with their eyes open and looked at a target placed at eye level, $2 \mathrm{~m}$ away. After subjects had stabilized themselves on the force platform, COP trajectories were measured for 60 seconds at a sampling rate of $20 \mathrm{~Hz}$. Measurements were carried out at 2, 4, and 6 weeks after admission, and progress over the 4 weeks of observation was evaluated.

Time series of COP were analyzed to define weightbearing asymmetry, body sway, and frequency. We investigated mean position (MP) in the mediolateral (M/L) direction, mean velocity (MV) in the $\mathrm{M} / \mathrm{L}$ and anteroposterior $(\mathrm{A} / \mathrm{P})$ directions, root mean square distance (RMSD) in the $\mathrm{M} / \mathrm{L}$ and $\mathrm{A} / \mathrm{P}$ directions, and power in the $\mathrm{M} / \mathrm{L}$ and $\mathrm{A} / \mathrm{P}$ directions based on frequency analysis.

The MP in the M/L direction is the mean value of the $\mathrm{X}$ axis increments of the COP time series data, [Equation (1)]. A positive value indicates the unaffected side and a negative value indicates the paretic side. The MP value in the $\mathrm{M} / \mathrm{L}$ direction was used in order to evaluate weight-bearing asymmetry.

$$
\mathrm{X}_{\mathrm{MP}}=\frac{1}{\mathrm{n}} \sum_{\mathrm{i}=1}^{\mathrm{n}} \mathrm{Xi}_{\mathrm{i}}(1)
$$

The MV values in the $\mathrm{M} / \mathrm{L}$ and $\mathrm{A} / \mathrm{P}$ directions are ratios of total length (LNG) of COP to measurement time, [Equations (2) and (3)]. The LNG values in the M/L and $\mathrm{A} / \mathrm{P}$ directions were defined as the sum of the incremental distances moved in the $\mathrm{X}$ and $\mathrm{Y}$ directions of the COP time series data.

$$
\begin{aligned}
& \mathrm{X}_{\mathrm{MV}}=\sum_{\mathrm{i}=1}^{\mathrm{n}}|\Delta \mathrm{xi}| / 60 \\
& \mathrm{Y}_{\mathrm{MV}}=\sum_{\mathrm{i}=1}^{\mathrm{n}}|\Delta \mathrm{yi}| / 60
\end{aligned}
$$

The RMSD values in the $\mathrm{M} / \mathrm{L}$ and $\mathrm{A} / \mathrm{P}$ directions were calculated using Equations (4) and (5). They are the root mean square values of the COP time series data displacements from the mean values of the respective directions. The MP value in the A/P direction was calculated in the same way as that of the M/L direction, [Equation (6)].

$$
\mathrm{X}_{\mathrm{RMSD}}=\sqrt{\frac{1}{\mathrm{n}} \sum_{\mathrm{i}=1}^{\mathrm{n}}\left(\mathrm{x}_{\mathrm{i}}-\mathrm{x}_{\mathrm{MP}}\right)^{2}}
$$

Table 2. Characteristics of impairment and disability

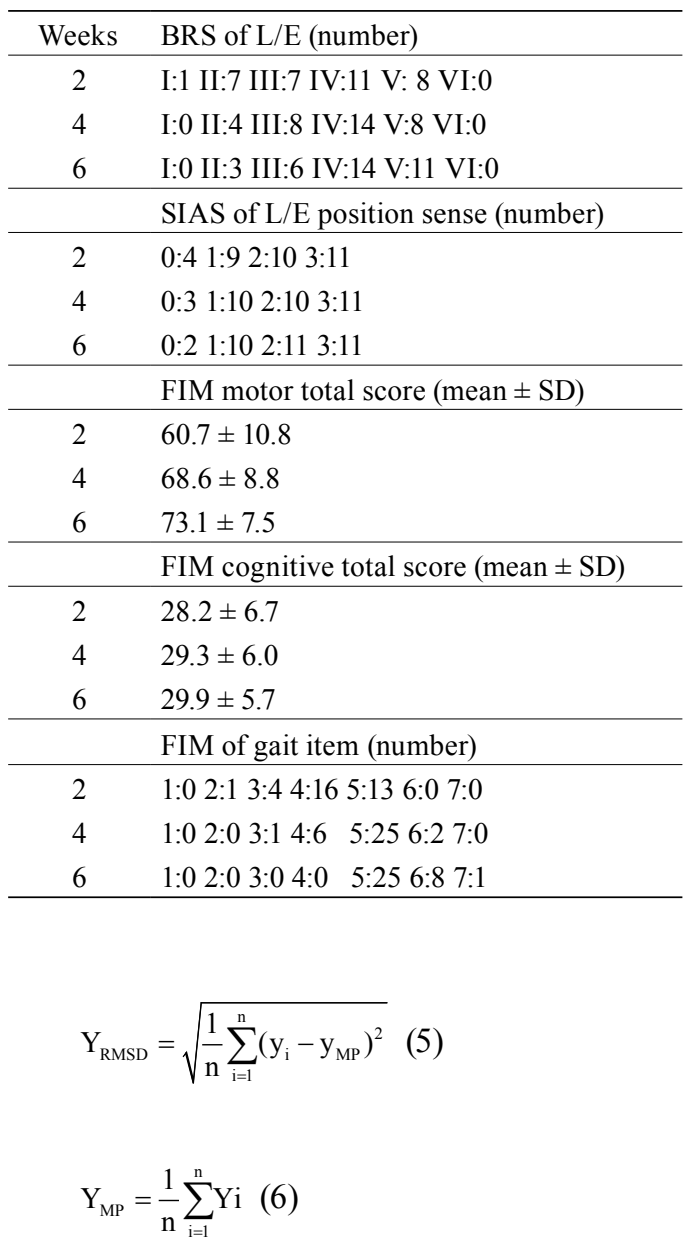

The MV and RMSD values in the M/L and A/P directions were used in order to evaluate body sway. The International Society of Posturography recommends the use of 2 COP-based measures: MV and RMSD ${ }^{12}$. MV represents the velocity of body sway and the RMSD is representative of the amplitude of body sway. Because postural control strategies in the $\mathrm{M} / \mathrm{L}$ and $\mathrm{A} / \mathrm{P}$ directions are controlled by different mechanisms $\left.{ }^{13}, 14\right)$, MV and RMSD were analyzed in both directions. In quiet standing, postural control in the $\mathrm{M} / \mathrm{L}$ direction is dominated by a loading/unloading response under the control of the hip abductors/adductors, and the $\mathrm{A} / \mathrm{P}$ direction is regulated by synergistic motor patterns of the ankle plantarflexion and dorsiflexion ${ }^{15)}$.

In addition, the improvement rates of MV and RMSD in the $\mathrm{M} / \mathrm{L}$ and $\mathrm{A} / \mathrm{P}$ directions over the 4 weeks period from 2 weeks post-admission were calculated using Equation. (7).

$$
\text { Improvement rate }=\frac{\text { value at } 2 \text { weeks }- \text { value at } 6 \text { weeks }}{\text { value at } 2 \text { weeks }} \times 100 \text { (7) }
$$

Frequency analysis was also performed to investigate the characteristics of body sway. Frequency analysis was performed by applying Fast Fourier Transforms to the time-series data and calculating the power spectrum. The international standard for evaluating the frequency interval of the power spectrum is $0.02-0.2 \mathrm{~Hz}, 0.2-2.0 \mathrm{~Hz}$, and $2.0-10.0 \mathrm{~Hz}^{12)}$. We used the power of each frequency band 
Table 3. Changes in mean position, mean velocity and root mean square distance

\begin{tabular}{clllll}
\hline \multirow{2}{*}{ Weeks } & Mean position & \multicolumn{2}{c}{ Mean velocity } & \multicolumn{2}{c}{ Root mean square distance } \\
\cline { 2 - 6 } & M/L direction & M/L direction & A/P direction & M/L direction & A/P direction \\
\hline 2 & $3.7 \pm 2.3$ & $1.78 \pm 0.99$ & $1.91 \pm 0.80$ & $0.86 \pm 0.43$ & $0.72 \pm 0.21$ \\
4 & $2.6 \pm 2.0^{* *}$ & $1.37 \pm 0.80^{* *}$ & $1.62 \pm 0.50^{* *}$ & $0.75 \pm 0.36$ & $0.66 \pm 0.17$ \\
6 & $2.7 \pm 2.0^{*}$ & $1.15 \pm 0.65^{* *}, \dagger$ & $1.49 \pm 0.54^{* *}$ & $0.63 \pm 0.30^{* *}$ & $0.60 \pm 0.14^{* *}$ \\
\hline
\end{tabular}

**: $p<0.01$ between 2 and $4 / 6$ weeks data, *: $<<0.05$ between 2 and $4 / 6$ weeks data, $\dagger: p<0.05$ between 4 and 6 weeks data

Table 4. Changes in power levels of each frequency band

\begin{tabular}{cccllll}
\hline \multirow{2}{*}{ Weeks } & \multicolumn{2}{c}{$0.02-0.2 \mathrm{~Hz}$} & \multicolumn{2}{c}{$0.2-2 \mathrm{~Hz}$} & \multicolumn{2}{c}{$2-10 \mathrm{~Hz}$} \\
\cline { 2 - 7 } & $\mathrm{M} / \mathrm{L}$ direction & $\mathrm{A} / \mathrm{P}$ direction & $\mathrm{M} / \mathrm{L}$ direction & $\mathrm{A} / \mathrm{P}$ direction & $\mathrm{M} / \mathrm{L}$ direction & A/P direction \\
\hline 2 & $0.37 \pm 0.39$ & $0.26 \pm 0.33$ & $0.48 \pm 0.67$ & $0.27 \pm 0.23$ & $0.01 \pm 0.02$ & $0.01 \pm 0.01$ \\
4 & $0.37 \pm 0.48$ & $0.22 \pm 0.15$ & $0.28 \pm 0.44^{* *}$ & $0.17 \pm 0.11^{* *}$ & $0.01 \pm 0.02^{* *}$ & $0.00 \pm 0.00^{* *}$ \\
6 & $0.22 \pm 0.30$ & $0.17 \pm 0.10$ & $0.14 \pm 0.17^{* *}, \dagger$ & $0.14 \pm 0.08^{* *}, \dagger$ & $0.00 \pm 0.00^{* *}, \dagger$ & $0.00 \pm 0.00^{* *}$ \\
\hline
\end{tabular}

**: $p<0.01$ between 2 and $4 / 6$ weeks data, $\uparrow: p<0.05$ between 4 and 6 weeks data

as a parameter.

Friedman's $\chi^{2}$ test was used to examine the significance of differences in $\mathrm{MP}$ in the $\mathrm{M} / \mathrm{L}$ direction, and $\mathrm{MV}$ and RMSD in the M/L and A/P directions of COP, among the three assessment times. When a significant change was found, the Bonfferroni method was used as a post -hoc test to confirm the significance. The paired t-test was used to compare the improvement rates of MV and RMSD in the $\mathrm{M} / \mathrm{L}$ and A/P directions. Significance was accepted for values of $\mathrm{p}$ less than 0.05. All statistical procedures were performed using SPSS version 19.0 (IBM Corp.).

\section{RESULTS}

Table 3 shows the mean and standard deviation of MP in the $\mathrm{M} / \mathrm{L}$ direction, $\mathrm{MV}$ in the $\mathrm{M} / \mathrm{L}$ and $\mathrm{A} / \mathrm{P}$ directions, and $\mathrm{RMSD}$ in the $\mathrm{M} / \mathrm{L}$ and $\mathrm{A} / \mathrm{P}$ directions at each measurement time. MP in the M/L direction significantly shifted to the center from the unaffected side during the 4-week observation period $(\mathrm{p}<0.05)$, and MP in the M/L direction was significantly shifted to the center from the unaffected side in the first 2 weeks of observation $(p<0.01)$, but did not improve thereafter.

$\mathrm{MV}$ in the $\mathrm{M} / \mathrm{L}$ and $\mathrm{A} / \mathrm{P}$ directions decreased significantly in the 4 -week observation period $(\mathrm{p}<0.01)$. Remarkably, the improvement rate in the $\mathrm{M} / \mathrm{L}$ direction $(40.2 \%)$ was significantly larger than that in the A/P direction (26.9\%) $(\mathrm{p}<0.01)$. MV in the $\mathrm{M} / \mathrm{L}$ direction decreased significantly both in the first 2 weeks $(\mathrm{p}<0.01)$, and also the second 2 weeks of observation $(\mathrm{p}<0.05)$. MV in the A/P direction decreased significantly in the first 2 weeks of observation ( $p$ $<0.01$ ), but did not significantly improve thereafter.

RMSD in the M/L and A/P directions decreased significantly in the 4 -week observation period $(\mathrm{p}<0.01)$. Remarkably, the improvement rate in the $\mathrm{M} / \mathrm{L}$ direction (35.0\%) was larger than that in the $\mathrm{A} / \mathrm{P}$ direction $(21.1 \%)$, but the difference was not significant. However, the differences in $\mathrm{RMSD}$ in the $\mathrm{M} / \mathrm{L}$ and $\mathrm{A} / \mathrm{P}$ directions were not significant in the first 2 weeks or the second 2 weeks of observation.

Table 4 shows the mean and standard deviation of the power levels of each frequency band at each measurement time. There were no significant differences in the power levels of the $0.02-0.2 \mathrm{~Hz}$ band in the $\mathrm{M} / \mathrm{L}$ and $\mathrm{A} / \mathrm{P}$ directions between any of the observation times. The power levels of the $0.2-2 \mathrm{~Hz}$ band in the $\mathrm{M} / \mathrm{L}$ and $\mathrm{A} / \mathrm{P}$ directions decreased significantly over the 4 -week observation period $(\mathrm{p}<0.01)$, as well as in the first 2 weeks $(\mathrm{p}<0.01)$, and the second 2 weeks $(p<0.05)$. The power levels of the $2-10 \mathrm{~Hz}$ band in the $\mathrm{M} / \mathrm{L}$ and $\mathrm{A} / \mathrm{P}$ directions decreased significantly in the 4-week observation period $(\mathrm{p}<0.01)$, and in the first 2 weeks $(p<0.01)$. In the second 2 weeks, the power level in the $M / L$ direction decreased significantly $(p<0.05)$, but that in the $\mathrm{A} / \mathrm{P}$ direction did not significantly different.

\section{DISCUSSION}

In this study, weight-bearing asymmetry diminished significantly and velocity and amplitude of body sway of post-stroke hemiplegic patients in the $\mathrm{M} / \mathrm{L}$ and $\mathrm{A} / \mathrm{P}$ directions decreased significantly in the 4-week period starting 2 weeks after hospital admission. In the improvement of body sway, the reduction in the $\mathrm{M} / \mathrm{L}$ direction was larger than that in the A/P direction. De Haart et al. ${ }^{16)}$ followed 37 stroke inpatients during their rehabilitation starting from the time they were able to stand independently for at least 30 seconds, on average 10 weeks post-stroke, and then 2 , 4,8 , and 12 weeks later. They reported that weight-bearing asymmetry diminished in the following 12 weeks, body sway in the $\mathrm{M} / \mathrm{L}$ and $\mathrm{A} / \mathrm{P}$ directions decreased gradually over the whole 12 weeks, and body sway in the M/L direction decreased significantly more than that in the $\mathrm{A} / \mathrm{P}$ direction. The results of our present study support their findings.

Reduction of body sway in the M/L direction was larger than that in the A/P direction. Hemiplegia after stroke causes a large perturbation in body sway in the $\mathrm{M} / \mathrm{L}$ direction compared to age-matched healthy controls ${ }^{16)}$. In 
post-stroke hemiplegia, a shift in the mean position of COP toward the unaffected side can compensate for the $\mathrm{A} / \mathrm{P}$ directional perturbation on the unaffected side, but cannot compensate for the $\mathrm{M} / \mathrm{L}$ directional perturbation. In other words, postural control of the $\mathrm{M} / \mathrm{L}$ direction is strongly affected by paralysis. Therefore, improvement in the M/L direction reflects improvement in paretic side functions arising from rehabilitation training.

This study focused on the recovery process of weightbearing asymmetry and body sway. Our results show that weight-bearing asymmetry diminished in the first 2 weeks, but did not improve thereafter. De Haart et al. ${ }^{16)}$ also reported that weight-bearing asymmetry diminished in the first 4 weeks, but did not improve thereafter. In the present study, the loading function of the paretic lower limb improved and the paretic leg contributed to postural control in the first 2 weeks. Considering the findings of Hase that overload on the paretic side might cause overcompensation on the unaffected side ${ }^{17}$, the optimum weight-bearing ratio should be the target of early stage rehabilitation after admission for stroke patients' independence in ADL.

In comparison with the study by De Haart et al. ${ }^{16)}$, which did not define the characteristics of the recovery process of body sway, this study showed that the velocity of body sway decreased significantly in the first 2 weeks of observation, whereas the amplitude decreased significantly over 4 weeks. The timing in improvement was different. The reason for early improvement of velocity of body sway may be explained by the results of frequency analysis. Body sway of a low frequency is associated with minimal effort and less stress for maintaining quiet standing balance ${ }^{18)}$, and the high frequency components of body sway reflect activity in response to activation of the graviceptive and proprioceptive loops ${ }^{19)}$. Since a significant decrease was shown by the high frequency bands (power of $0.2-2,2-10 \mathrm{~Hz}$ band) in the first 2 weeks of observation, sensory feedback from the unaffected side may have contributed to the early improvement of velocity of body sway. Late improvement of amplitude of body sway is possibly explained by age-related changes during quiet standing, since Abrahamova et al. reported that the most sensitive COP parameter for detecting balance change was RMSD, and RMSD reflects the time taken for integrated processing of sensory inputs ${ }^{20}$. When the proprioceptive information from the feet and ankles is artificially altered, normal subjects are compelled to rely more on other sensory (visual and vestibular) input ${ }^{21}$. However, hemiplegics, who often have visual, vestibular, and somatosensory disturbance ${ }^{17}$ ), have difficulty in coordinating these inputs, and thus much time is required to improve RMSD by rehabilitation.

Despite numerous intervention studies aimed at improving standing postural control, no definitive conclusion on the best approach to facilitate the recovery of standing postural control of post-stroke hemiplegia patients has been arrived $\mathrm{at}^{22,23)}$. One reason for this is the lack of adequate assessment of standing postural control. A limitation of the present study was the assessment of only COP. There are many ways of assessing postural control including COP measurements, as used in this study, alignment research with kinematics, and assessment of functional improvement in the paretic lower limb using EMG.

In conclusion, the amplitude of body sway of post-stroke hemiplegic patients requires a longer time to show significant improvement than weight-bearing asymmetry and velocity of body sway. Although the loading on the paretic lower limb improves at an early stage, attainment of optimum postural control, including management of the affected paretic lower limb, requires much time. We should emphasize standing training for the paretic lower limb in accordance with improvement in paretic function to facilitate the recovery of standing postural control.

\section{REFERENCES}

1) Shumway-Cook A, Woolacott M: Motor Control. Translating Research into Clinical Practice, 2nd ed. Lippicott Williams \& Wilkins, 2007, pp $164-165$.

2) Laufer Y, Sivan D, Schwarzmann R, et al.: Standing balance and functional recovery of patients with right and left hemiparesis in the early stages of rehabilitation. Neurorehabil Neural Repair, 2003, 17: 207-213. [Medline] [CrossRef]

3) Genthon N, Rougier P, Gissot AS, et al.: Contribution of each lower limb to upright standing in stroke patients. Stroke, 2008, 39: 1793-1799. [Medline] [CrossRef]

4) Peurala SH, Könönen P, Pitkänen K, et al.: Postural instability in patients with chronic stroke. Restor Neurol Neurosci, 2007, 25: 101-108. [Medline]

5) Suzuki K, Nakamura R, Yamada Y, et al.: Relationship between maximum walking speed and standing balance in hemiparetic stroke patients. Jpn J Rehabil Med, 1992, 29: 577-580. [CrossRef]

6) Sackley CM: Falls, sway, and symmetry of weight-bearing after stroke. Int Disabil Stud, 1991, 13: 1-4. [Medline] [CrossRef]

7) Shim S, Yu J, Jung J, et al.: Effects of dual-task performance on postural sway of stroke patients with experience of falls. J Phys Ther Sci, 2012, 24: 975-978. [CrossRef]

8) Brunnstrom S: Motor testing procedures in hemiplegia: based on sequential recovery stages. Phys Ther, 1966, 46: 357-375. [Medline]

9) Chino N, Sonoda S, Domen K, et al.: Stroke Impairment Assessment Set (SIAS) - A new evaluation instrument for stroke patients. Jpn J Rehabil Med, 1994, 31: 119-124. [CrossRef]

10) Tsuji T, Liu M, Sonoda $S$, et al.: The stroke impairment assessment set: its internal consistency and predictive validity. Arch Phys Med Rehabil, 2000, 81: 863-868. [Medline] [CrossRef]

11) Data management service of the Uniform Data System for Medical Rehabilitation and the Center for Functional Assessment Research: Guide for Use of the Uniform Date Set for Medical Rehabilitation, Version 3.1. Buffalo: State University of New York at Buffalo, 1990.

12) Kapteyn TS, Bles W, Njiokiktjien CJ, et al.: Standardization in platform stabilometry being a part of posturography. Agressologie, 1983, 24: $321-$ 326. [Medline]

13) Winter DA, Prince F, Frank JS, et al.: Unified theory regarding A/P and $\mathrm{M} / \mathrm{L}$ balance in quiet stance. J Neurophysiol, 1996, 75: 2334-2343. [Medline]

14) Gatev P, Thomas S, Kepple T, et al.: Feedforward ankle strategy of balance during quiet stance in adults. J Physiol, 1999, 514: 915-928. [Medline] [CrossRef]

15) Winter DA, Prince F, Stegiou P, et al.: Medial-lateral and anterior-posterior motor responses associated with centre of pressure changes in quiet standing. Neurosci Res Commun, 1993, 12: 141-148.

16) de Haart M, Geurts AC, Huidekoper SC, et al.: Recovery of standing balance in postacute stroke patients: a rehabilitation cohort study. Arch Phys Med Rehabil, 2004, 85: 886-895. [Medline] [CrossRef]

17) Hase K: Standing posture Analysis. Jpn J Rehabil Med, 2010, 47: 591-596.

18) Lee GE, Bae H, Yoon TS, et al.: Factors that influence quiet standing balance of patients with incomplete cervical spinal cord injuries. Ann Rehabil Med, 2012, 36: 530-537. [Medline] [CrossRef]

19) Dichgans J, Mauritz KH, Allum JH, et al.: Postural sway in normals and atactic patients: analysis of the stabilising and destabilizing effects of vision. Agressologie, 1976, 17: 15-24. [Medline]

20) Abrahamová D, Hlavacka F: Age-related changes of human balance during quiet stance. Physiol Res, 2008, 57: 957-964. [Medline]

21) Choy NL, Brauer S, Nitz J: Changes in postural stability in women aged 20 
to 80 years. J Gerontol A Biol Sci Med Sci, 2003, 58: 525-530. [Medline] [CrossRef]

22) Pollock A, Baer G, Pomeroy VM, et al.: Physiotherapy treatment approaches for the recovery of postural control and lower limb function following stroke. Cochrane Datebase Syst Rev, 2007, CD001920.

23) Geurts AC, de Haart M, van Nes IJ, et al.: A review of standing balance recovery from stroke. Gait Posture, 2005, 22: 267-281. [Medline] [CrossRef] 